\title{
GAYA POP ART SEBAGAI IDE DASAR PERANCANGAN ULANG CORPORATE IDENTITY DAN PROMOSI BARBERSON HAIRCUT
}

\author{
Arif Suryawan $^{1}$, Handriyotopo $^{2}$ \\ Prodi S1-Desain Komunikasi Visual \\ Fakultas Seni Rupa dan Desain, Institut Seni Indonesia (ISI) Surakarta \\ Jl. Ringroad Km 5,5 Mojosongo Surakarta 57127 Jawa Tengah \\ 1Email : arifsuryawan11@gmail.com \\ 2Email : handriyo@isi-ska.ac.id
}

\begin{abstract}
Barberson Haircut is a company engaged in hair shaving services, located in Ceper, Klaten. Barberson Haircut does not have a corporate identity that is consistent, difficult to recognize and less attractive. Through a qualitative research approach and swot analysis to find out the strengths needed in designing a new visual identity with the right stages of identity design. Redesign of corporate identity with pop art style as a visual creative strategy so that consumers are more familiar with Barberson Haircut. Based on the design stages and the creative strategy of the advertising, the results of this design are in the form of logos, stationery sets, merchandising, and promotional media. The benefits of this design are to provide a new identity to distinguish Barberson Haircut from other barbershop, and introduce Barberson Haircut to the audience.
\end{abstract}

Keywords: Corporate Identity, Barbershop, Pop Art, Promotion

\section{PENDAHULUAN}

\section{Latar Belakang}

Perkembangan bisnis saat ini mengalami peningkatan yang cukup pesat, untuk mengatasi hal tersebut suatu perusahaan dituntut untuk lebih kreatif. Sebuah perusahaan layaknya seorang manusia yang membutuhkan suatu identitas untuk membedakan dengan perusahaan lain. Bukan hanya sekedar identitas nama saja, namun juga diperlukan tampilan visual yang meliputi logo dan corporate identity agar perusahaan memiliki karakter di mata masyarakat. Identitas korporat (corporate identity) menurut M. Linggar Anggoro (2000: 280) adalah suatu cara atau suatu hal yang memungkinkan suatu perusahaan dikenal dan dibedakan dari perusahaan-perusahaan lainnya. Ia juga menyebutkan bahwa identitas perusahaan harus diciptakan melalui suatu rancangan desain khusus yang meliputi hal-hal unik atau khas tentang perusahaan yang bersangkutan secara fisik. Pada dasarnya perusahaan memerlukan corporate identity yang berupa logo atau merek dan aplikasinya sesuai dengan kebutuhan perusahaan, karena corporate identity merupakan cara yang tepat untuk menarik perhatian konsumen. Karakter yang kuat dapat memposisikan citra dari suatu perusahaan, jadi identitas sangatlah diperlukan dalam menunjukkan citra yang ingin diperkenalkan pada khalayak. Semakin gencarnya persaingan antar perusahaan membuat citra menjadi sebuah ciri yang menonjol dari masing masing perusahaan. 
Salah satu usaha yang juga memerlukan corporate identity adalah Barbershop. Barbershop merupakan salah satu usaha yang mulai berkembang di Indonesia, dimana barbershop dapat memenuhi kebutuhan masyarakat khususnya kaum pria atas kebutuhan akan penampilannya. Sikap konsumen dan minat untuk memakai pelayanan jasa barbershop dipengaruhi beberapa hal seperti harga, lokasi, promosi, dan yang paling utama adalah pelayanannya. Kemampuan tukang cukur dalam mengolah berbagai gaya rambut pria yang kekinian juga menjadi keunggulan barbershop. Diantara banyaknya barbershop, Barberson Haircut merupakan salah satu perusahaan yang bergerak di bidang jasa cukur rambut, berdiri pada tahun 2016 dan berlokasi di Ceper, Klaten. Barberson Haircut memiliki potensi yang besar untuk berkembang jauh lebih besar serta berpotensi untuk membuka banyak cabang di kota lain. Potensi potensi tersebut dapat dimaksimalkan apabila Barberson Haircut memiliki corporate identity dan promosi yang menarik. Namun sejauh ini, Barberson Haircut belum memiliki corporate identity yang konsisten. Berdasarkan segi desain komunikasi visual, logo barbershop tampil kurang menarik dan tidak mudah dikenali, hal ini dibuktikan dengan adanya perbedaan desain atau penanda toko yang tidak konsisten dan kurang mencerminkan identitas perusahaan. Oleh karena itu Barberson Haircut harus merancang corporate identity untuk menarik konsumen supaya lebih mengenal Barberson Haircut agar mempunyai ciri khas pembeda dari barbershop lain.
Berdasarkan latar belakang yang telah dijabarkan, maka perlu dilakukan perancangan ulang corporate identity untuk Barberson Haircut. Corporate identity yang akan dibuat berupa logo dan desain promosi melalui ilustrasi gaya pop art. Gaya pop art diambil sebagai treatment desain karena kesan artistik, berani serta colourfull, mencerminkan anak muda bergaya urban yang ceria dan sangat masa kini. Karakteristik culture barbershop haircut dan pendekatan visual pop art tersebut menjadi kekuatan referensi visual untuk merancang ulang corporate identitiy dengan rancangan sederhana dan mudah dipahami sehingga konsumen akan mudah mengenalinya.

Tujuan dari perancangan corporate identity Barberson Haircut ini antara lain adalah:

a. Merancang corporate identitiy dengan gaya pop art yang konsisten dan mampu menggambarkan karakter perusahaan.

b. Merancang media promosi untuk memperkenalkan corporate identitiy Barberson Haircut yang baru kepada konsumen.

\section{A. Corporate identitiy (Identitas Perusa- haan)}

Menurut Jefkins (1997:296) corporate identitiy berarti menyeragamkan penampilan fisik tertentu dari salah satu atau beberapa aspek perusahaan, dapat memperkuat usaha periklanan dan juga berfungsi memberikan efek repetisi (pengulangan) sehingga akan membuat usaha-usaha periklanan lebih efektif. Seperti penggunaan warna yang sama, logo yang sama dan tipografi 
(bentuk-bentuk huruf) yang sama. Diperlukan teori-teori yang mendukung guna membangun sebuah perancangan corporate identitiy untuk Barberson Haircut yang berkarakter, sehingga mampu menanamkan suatu brand yang baik kepada konsumen.

\section{B. Logo untuk menggambarkan Citra perusahaan}

Logo merupakan atribut utama yang terlihat secara fisik, seperti layaknya wajah manusia pada umumnya. Melalui logo, tergambar atribut non fisik lainya sebagai jiwa dari etintas tersebut yaitu, visi dan misi, corporate value, corporate culture, dan seluruh kepribadiannya. Pencarian ide logo harus berdasarkan etintas tersebut. Jadi yang tampak dipermukaan benar-benar berasal dari dalam dirinya (Rustan, 2009 : 66). Rustan (2009:42) mengatakan bahwa ada dua kriteria utama pada logo. Pertama adalah logo harus unik, mencerminkan dan mengangkat citra entitasnya sekaligus membedakan dengan yang lain. Kedua, logo harus fleksibel sekaligus tahan lama.

\section{Gaya pop art pada desain grafis}

Momentum kejayaan pop art terjadi pada dekade 60-an silam, namun kehadiran gaya pop art seperti yang biasa kita lihat di dalam karyakarya Andy Warhol dan Roy Lichtenstein masih bisa kita nikmati salah satunya lewat karyakarya desain grafis yang ada di sekitar kita. Di Indonesia sendiri, karya desain grafis yang mengusung gaya pop art telah merebak pada sekitar tahun 70-an. Pada saat itu, Majalah musik aktual, salah satu majalah musik yang sangat populer di kalangan generasi muda menyerap gaya pop ke dalam berbagai bentuk ilustrasi, poster, dan desain halaman/rubrik yang ada di dalam majalah tersebut (Sachari \& Sunarya, 2002 : 118). Dengan denikian gaya Pop Art sebagai ide dasar dalam perancangan ulang adalah tepat, untuk mengangkat brand Babershop Haircut sesuai zamanya saat ini yang kembali ke pop art. Maka sebagai bentuk ilustrasi dalam persuasi periklanan dan strategi visual indentitas, dengan pangsa pasar anak muda milenial pendekatan kreatif visual adalh usaha untuk mendekatka diri dengan pasar.

\section{Promosi untuk menciptakan brand awareness}

Pengertian promosi Menurut Michael Ray dalam buku Morrisan M.A (2010:16) mendefinisikan promosi adalah kordinasi dari seluruh upaya yang dimulai pihak penjual untuk membangun berbagai saluran informasi dan persuasi untuk menjual barang dan jasa atau memperkenalkan suatu gagasan. Pembuatan promosi ini tentu diterapkan pada media-media, yang disebut media promosi. Handriyotopo (2018:125) dalam pernyataannya tentang kesadaran merek dalam kontek pemasaran secara umum dan awareness yang kuatterhadap merek (brand loyalty) yang dikembangkan kepada simbol-simkbol visual maka;

1). Mampu memberikan kesadaran kuat akan Loyalitas merek (awareness for brand loyalty)

2). Mampu memberikan rasa sentuhan kuat kepada prestasi merek 


\section{(brand a touch achievement)}

3). Mampu membentuk kualitas merek (brand quality)

4). Memberikan citra atau nilai tertentu kepada merek (brand of benefit value)

5). Menjadi sebuah aset komunikasi yang komunikatif terhadap produk (brand of communication asset).

Melihat merek tersebut maka dengan demikian jika melihat posisi brand Barberson Haircut adalah untuk menimbulkan kesadaran kembali tentang posisinya di pasar sebagai perusahaan pada produk jasa layanan potong rambut yang cukup diperhitungkan di Klaten, maka dengan perancangan ulang dan strategi promosi yang baru harapannya adalah konsumen akan menjadi lebih loyal, terhadap brand baru yang diperkenalkan saat ini.

Menurut Terence A. Shimp (2000:7) Promosi memiliki lima fungsi yang sangat penting bagi suatu perusahaan/lembaga. Kelima fungsi tersebut dijabarkan sebagai berikut :

1) Informing (Memberikan Informasi) Promosi menampilkan peran informasi bernilai lainnya, baik untuk merek yang diiklankan maupun konsumennya, dengan mengajarkan manfaat-manfaat baru dari merek yang telah ada.

\section{2) Persuading (Membujuk)}

Media promosi atau iklan yang baik akan mampu mempersuasi pelanggan untuk mencoba produk dan jasa yang ditawarkan. Terkadang persuasi berbentuk mempengaruhi permintaan primer, yakni menciptakan permintaan bagi keseluruhan kategori produk. Lebih sering promosi berupaya untuk membangun permintaan sekunder, permintaan bagi merek perusahaan yang spesifik.

3) Reminding (Mengingatkan)

Iklan menjaga agar merek perusahaan tetap segar dalam ingatan para konsumen. Saat kebutuhan muncul, yang berhubungan dengan produk dan jasa yang diiklankan, dampak promosi di masa lalu memungkinkan merek pengiklan hadir di benak konsumen.

4) Adding Value (Menambah nilai)

Terdapat tiga cara mendasar dimana perusahaan bisa memberi nilai tambah bagi penawaran-penawaran mereka, inovasi, penyempurnaan kualitas, atau mengubah persepsi konsumen. Promosi yang efektif menyebabkan merek dipandang lebih elegan, lebih bergaya, lebih bergengsi, dan bisa lebih unggul dari tawaran pesaing. 
5) Assisting (Mendampingi upayaupaya lain dari perusahaan)

Periklanan merupakan salah satu alat promosi. Promosi membantu perwakilan penjualan. Iklan mengawasi proses penjualan produk-produk perusahaan dan memberikan pendahuluan yang bernilai bagi wiraniaga sebelum melakukan kontak personal dengan para pelanggan yang prospektif. Upaya, waktu, dan biaya periklanan dapat dihemat karena lebih sedikit waktu yang diperlukan untuk memberi informasi kepada prospek tentang keistimewaan dan keunggulan produk jasa.

Berdasarkan atas dasar teori di atas, maka strategi promosi baru menjadi kata kunci untuk pengingat kembali keberadaan Babershop Haircut sebagai layanan jasa potong rambut yang mumpuni. Dengan strategi periklanan yang baik maka identitas yang baru mampu menjadi pengingat atas brand Babershop Haircut dan memiliki nilai tambah yang lebih baik. Melalui perancangan media yang tepat sasaran adalah untuk mendapatkan impact yang cukup significant atas konsumennya.

\section{E. Barberson Haircut}

Pada awal tahun 2016 menjadi momentum awal berdirinya bisnis jasa cukur rambut Barberson Haircut, banyak faktor yang menjadi pertimbangan dari segi bisnis dan hobi, akhirnya menjadi pertimbangan Arsyad, pria asal Klaten ini untuk mendirikan sendiri usaha jasa cukur rambut khusus pria yang bernama Barberson Haircut. Nama Barberson berasal dari kata Barber yang berarti tukang cukur atau pemangkas rambut dan Son yang berarti anak laki-laki. Barberson Haircut mempunya visi sebagai pilihan utama dalam pelayanan jasa cukur rambut. Misinya Mengenalkan berbagai layanan dan keunggulan Barberson Haircut sebagai jasa cukur rambut yang modern. Barberson Haircut sendiri menggunakan alat yang modern yang berkualitas dan mendukung keefektifan dan keefisienan dalam kegiatan operasional. Serta melakukan inovasi secara berkelanjutan terhadap keseluruhan sistem Barberson Haircut.

Barberson Haircut terletak di Jl. Ceper, Jagah, Kurung, Ceper, Kabupaten Klaten, Daerah ceper Terletak sekitar $10 \mathrm{~km}$ arah utara Klaten sepanjang jalan raya Klaten-Solo. Kecamatan Ceper terdiri dari 18 Kelurahan/Desa. Sebelah barat berbatasan dengan Kecamatan Ngawen, dan Kecamatan Karanganom. Sebelah selatan berbatasan dengan Kecamatan Trucuk dan Kecamatan Klaten Utara. Sebelah timur berbatasan dengan Kecamatan Pedan. Sebelah utara berbatasan dengan Kecamatan Delanggu. Berada di tempat yang strategis, mudah dijangkau dengan kendaraan umum tak jauh dari keramaian. Dari segi ruangan yang bersih dan fasilitas yang lengkap disertai dengan pelayanan yang maksimal membuat konsumen semakin nyaman. Fasilitas istimewa yang ditawarkan Barberson Haircut antara lain yang lain pengguntingan rambut dan shaving (mencukur kumis serta juga jenggot) serta juga trimming (Perawatan 
dan penumbuh kumis dan jambang).

Barberson Haircut memiliki potensi yang sangat besar untuk berkembang jauh lebih besar lagi serta berpotensi pula untuk membuka banyak cabang di Kota lain. Potensi potensi tersebut dapat dimaksimalkan melalui media promosi yang akan dirancang. Selain tempat dan pelayanan cukur rambut yang mengutamakan kepuasan konsumen, Barberson Haircut pula memberikan pelayanan ekstra, dimana banyak sekali promosi-promosi yang di gencarkan seperti $8 \mathrm{x}$ potong gratis $1 \mathrm{x}$ potong, beli pomade gratis potong, untuk yang hari ulang tahun bisa gratis potong rambut syaratnya menunjukan Tanda Pengenal/Ktp dan lain sebagainya.

\section{METODE}

\section{A. Metode Penelitian}

Metode penelitian yang digunakan dalam penyusunan tugas akhir perancangan ini adalah metode kualitatif menurut Sugiyono (2015:19) metode penelitian kualitatif terdapat 3 tahapan yaitu deskriptif, reduksi, dan seleksi. Pada tahapan awal ini peneliti akan langsung melakukan pengamatan di lapangan dan mendapatkan informasi yang bervariasi setelah itu tahap ke 2 disebut tahap reduksi, di tahap ini peneliti memfokuskan masalah tertentu. Kemudian tahap ke 3 yaitu seleksi, pada tahap ini akan menguraikan fokus yang telah ditetapkan menjadi lebih ringkas.

\section{B. Metode Analisis Data}

Penelitian dalam perancangan Corporate iden- titiy ini menggunakan analisis SWOT. Analisis SWOT adalah suatu cara menganalisis faktor-faktor internal dan eksternal menjadi langkah-langkah strategi dalam pengoptimalan usaha yang lebih menguntungkan. Dalam analisis faktor-faktor internal dan eksternal akan ditentukan aspek-aspek yang menjadi kekuatan (strengths), kelemahan (weakness), kesempa$\tan$ (opportunities), dan yang menjadi ancaman (treathment) sebuah perusahaan.

Kekuatan (strenghts) :

a. Barberson Haircut sangat mengutamakan kepuasan konsumen.

b. Selalu berinovasi.

c. Pelayanan yang ramah.

d. Berlokasi strategis.

e. Harga terjangkau.

Kelemahan (weaknesses)

a. Dekorasi yang kurang menarik.

b. Promosi yang belum maksimal.

c. Belum mempunyai ciri khas.

d. Masih dalam proses pengembangan sistem

e. Hanya memiliki 1 gerai

Peluang (opportunities) :

a. Lokasi yang strategis di pinggir jalan.

b. Apabila corporate identity Barberson Haircut di perkuat dan dibuat konsisten maka akan mampu bersaing.

c. Ada keinginan untuk membuka cabang di daerah lain.

Ancaman (threats) : 
a. Banyaknya barbershop baru dengan inovasi dan ide ide yang lebih segar.

b. Beberapa barbershop di Kota besar sudah memakai alat-alat yang modern.

c. Perkembangan zaman yang menuntut permintaan konsumen yang beranekaragam.

Atas dasar SWOT analisis di atas, maka strategi visual sebagai ide dasar penciptaan identitas visual yang baru dengan pendekatan gaya pop art diharapakan mampu memiliki kekuatan baru atas visi misi perusahaan tidak sekedar remainding, tetap added value yang lebih terhadap loyalitas merek Babershop Haicut itu sendiri.

\section{Metode Perancangan}

\section{Metode Perancangan Logo}

Tahapan kerja perancangan logo Barberson Haircut akan menggunakan teori menurut Surianto Rustan dalam bukunya Mendesain logo (2013:36) yaitu:

a) Riset dan analisis

Mencari Fakta-fakta tentang entitas, termasuk pesaingnya. Apabila entinitas adalah sebuah perusahaan maka yang diriset pertama kali adalah sektor industri, visi, misi, struktur, target market, keunggulan dan kelemahan (analisis SWOT) dan lain-lain.

b) Thumbnails

Berdasarkan creative brief, kemudian di buat thumbnails yang merupakan visual brainstorming atau cara pengembangan ide lewat visual, berupa sketsa-sketsa kasar dilakukan secara manual.

c) Komputer atau Digitalisasi
Pada tahap berikutnya, beberapa thumbnails yang berpotensi dipilih, lalu di pindahkan ke komputer untuk dibuat digitalisasinya .

d) Review

Setelah terkumpul alternatif desain yang sudah diedit dan di rapikan, tahap selanjutnya adalah di review.

e) Sistem identitas

Pada tahap ini untuk menentukan atribut lainya seperti logo turunan, sistem warna, sistem tipografi, sistem penerapan logo pada berbagai media, dan lain-lain.

f) Produksi

Berdasarkan sistem identitas, kemudian seluruh media diproduksi berupa prototype.

\section{Metode Perancangan Media Promosi}

Metode perancangan media promosi Barberson Haircut akan menggunakan teori menurut Rama Kartamukti dalam bukunya "strategi Kreatif Dalam Periklanan", berikut tahapan yang harus dilakukan dalam mencereranakan media promosi :

a. Menentukan target audience atau khalayak sasaran

Pada proses ini hal yang pertama dan utama adalah memastikan target audiencenya, karena identifikasi target audience yang matang akan memperlancar tahap selanjutnya dan punya andil besar terhadap sukses tidaknya sebuah kampanye pemasaran. Target audien adalah khalayak konsumen yaitu kaum muda laki-laki di Kelaten.

b. Menentukan tujuan beriklan

Harus jelas tujuan dari promosi yang akan dilakukan itu seperti apa, apakah untuk membangun sebuah brand aware- 
ness, knownledge atau yang lainya. Tujuan yang dibangun dalan media promosi dan identitas visual yang baru tidak sekedar kesadaran dan pengetahuan saja, harapnya adalah mereka setia kepada merek untuk menjadi pelanggan yang tetap.

c. Pemilihan media

Menyeleksi media yang tepat agar pesan sampai ke konsumen. Pemiliohan media promosi yang tepat sasaran adalah penting. Strategi pertama adalah melalui periklanan surat kabat lokal, dan di endors melalui media elektronik atau media sosial online, untuk mendapatkan impact yann bagus bagi konsumen milenial.

d. Menentukan pesan apa yang akan disampaikan

Setelah melakukan semua tahapan, maka selanjutnya dilakukan adalah membuat perancangan pesan yang akan disampaikan. Pesan yang ingin disampaikan adalah kesadaran merek dan loyalitas merek bahwa Babershop Haircut memiliki layanan baru yang tidak sekedar tukang cukur biasa.

\section{PEMBAHASAN}

\section{Konsep Kreatif}

\section{Strategi Kreatif}

Strategi kreatif merupakan langkah untuk menyampaikan pesan dari seorang desainer atau perancang kepada masyarakat secara luas. Hal ini penting karena pesan yang disampaikan kepada target harus dapat diterima dengan baik. Identitas visual Barberson Haircut dirancang secara kreatif dan komunikatif supaya mampu menyampaikan citra baik dari Barberson Haircut. Untuk mencapai brand awareness pada target audiencenya maka perlu adanya tindakan atau proses kreatif berupa re-design atau perancangan ulang logo, perbaikan dalam sinkronisasi aplikasi corporate identity nya dan promosinya serta pemilihan maupun penambahan media promosi.

\section{Konsep Media}

1. Strategi media

Perancangan media promosi ini tidak hanya dibuat dan dicetak tetapi harus ada strategi dalam peletakan dan penempatannya agar media tersebut dapat menyampaikan pesannya secara efektif kepada konsumen sasarannya. Pemilihan media yang tepat dalam mempromosikan Babershop Haircut adalah poster, instagram, merchandising, stickercar, dan surat kabar, dengan sepsifikasi media sebagai berikut;

\begin{tabular}{|c|c|c|c|}
\hline No & $\begin{array}{l}\text { Media yang } \\
\text { digunakan }\end{array}$ & Strategi Media & $\begin{array}{l}\text { Tempat penayangan/ } \\
\text { Jadwal penayangan }\end{array}$ \\
\hline 1 & Poster & $\begin{array}{l}\text { Ditempel di tempat-tempat } \\
\text { transportasi umum seperti } \\
\text { terminal, alun-alun dan lain-lain }\end{array}$ & $\begin{array}{l}\text { Papan Informasi, } \\
\text { Persimpangan jalan/3bulan } \\
\text { sebelum event }\end{array}$ \\
\hline 2 & $\begin{array}{l}\text { Media Sosiall } \\
\text { instagram }\end{array}$ & $\begin{array}{l}\text { Share melalui akun Barberson } \\
\text { mengounakan caption dan } \\
\text { hastag yang menarik }\end{array}$ & $\begin{array}{l}\text { Media sosial } \\
\text { instagram/3bulan } \\
\text { sebelum event }\end{array}$ \\
\hline 3 & Merchandise & $\begin{array}{l}\text { Di dispaly di booth Barberson Haircut } \\
\text { di Event Musik Akhir Tahun Klaten }\end{array}$ & $\begin{array}{l}\text { Event Musik Akhir Tahun Klaten/ } \\
\text { saat event berlangsung }\end{array}$ \\
\hline 4 & Stickercar & Ditempel di tempat transportasi umum & Kaca belakang Mobil/1bulan \\
\hline 5 & Surat Kabar & Menggunakan Surat kabar SOLOPOS & SOLOPOS/1minggu \\
\hline
\end{tabular}

Gambar 1. Tabel Strategi Media

(Sumber: Arif Suryawan, 2019)

\section{Konsep Perancangan}

1. Kreatif Brief

a. Isu yang ingin dikomunikasikan: Identitas Barberson Haircut yang menampilkan karakteristik belum ada. Banyak orang ke- 
bingungan untuk membedakan Barberson Haircut dengan barbershop lain yang berada di Klaten khususnya Kecamatan Ceper. Berdasarkan hal tersebut perlu adanya sebuah identitas visual yang baru dan berkarakter sebagai pembeda Barberson Haircut dengan barbershop yang lainnya.

b. Segmentasi : Pria Berusia 15 tahun ke atas, kaum metroseksual dan juga para masyarakat bergaya hidup urban berada di Klaten atau luar kota, yang sangat tertarik dengan dunia fashion dan lifestyle.

c. Tone and manner: Modern, elegant dan Karakteristik

d. Positioning: Sebagai Tempat Jasa cukur rambut yang berada di Ceper, Klaten.

e. Mandatory: Menggunakan unsur culture barbershop dan warna pop sebagai karakteristik desain.

\section{A. Desain Logo}

Untuk mendesain sebuah logo, tahap awal yang dilakukan adalah menentukan objek apa saja yang akan divisualkan. Berikut ini beberapa visual yang digunakan untuk perancangan logo Barberson Haircut.
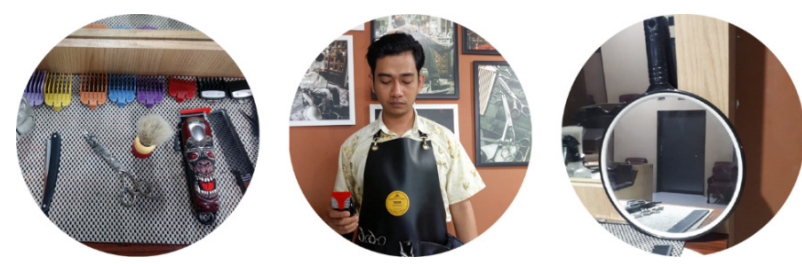

Gambar 2. Objek Visual Barbershop

(Sumber : Arif Suryawan, 2019)
1. Proses Sketsa Logo/Thumbnails

Unsur pendukung berupa objek-objek yang dibutuhkan pada perancangan logo dan berhubungan dengan haircut diantaranya nama, pria, alat clipper, sisir, razor, cermin, appron dan tiang barbershop. Berdasarkan solusi visual pada setiap elemennya akan digabungkan sehingga tercipta karakter baru. Berikut beberapa sketsa logo yang didapat:
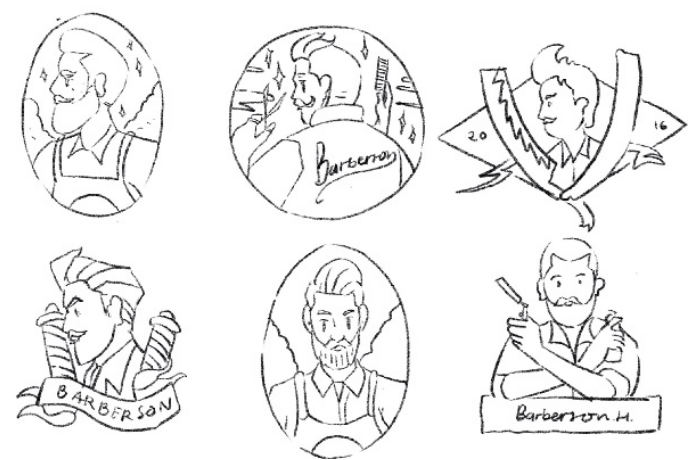

Gambar 3. Sketsa Logo Barberson Haircut

(Sumber : Arif Suryawan, 2019)

\section{Digitalisasi}

Dari beberapa alternatif sketsa logo dipilihlah sketsa yang sesuai dengan karakter dan image Barberson Haircut. Maka didapatlah beberapa logogram di bawah ini :
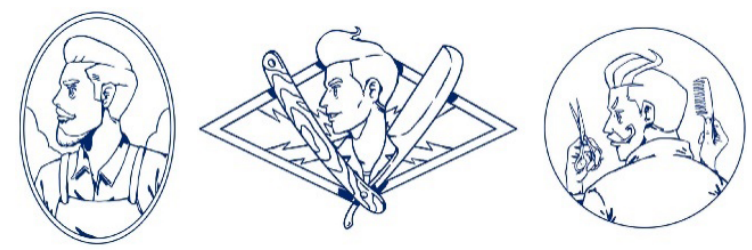

Gambar 4. Digitalisasi Logo Barberson Haircut (Sumber : Arif Suryawan, 2019)

Kemudian setelah logogram didapat, langkah selanjutnya adalah pemilihan tipografi yang nantinya akan digunakan sebagai logotype. Pemilihan disesuaikan dengan konsep serta disesuaikan dengan logogram. Berikut beberapa alternatif pemilihan tipografi yang akan digunakan untuk logotype.

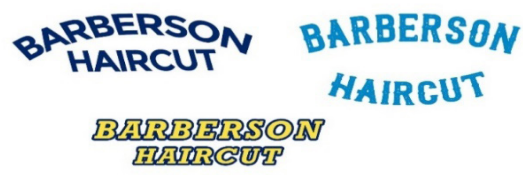

Gambar 5. Alternatif Tipografi Logo Barberson Haircut 
(Sumber : Arif Suryawan, 2019)

Alternatif tipografi yang digunakan untuk logotype adalah Campground Monoline font. Font ini mengkombinasikan font dengan gaya yang berbeda antara skrip \& sans, selanjutnya Montserrat-Regular font ini menggunakan gaya huruf sans serif, dan yang terakhir ada Triumph Wheels Rough Font, font ini adalah font decorative yang menampilkan kesan berkarakter, memiliki keterbacaan yang jelas dan sesuai bila disandingkan dengan logogram yang terpilih.
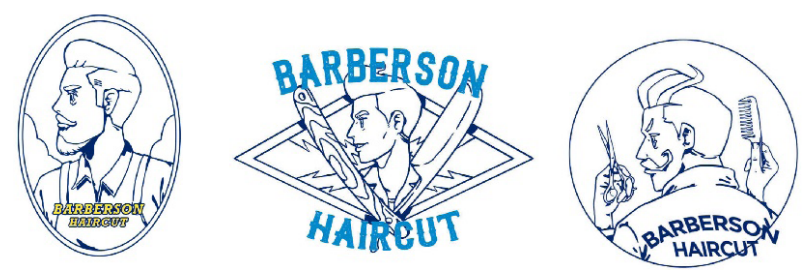

Gambar 6. Alternatif Tipografi dan Logo Barberson Haircut

(Sumber : Arif Suryawan, 2019)

Setelah menggabungkan logogram dan logotype, logo diberi warna sesuai dengan konsep pop art dengan memilih warna biru dan kuning untuk menggambarkan kegembiraan, optimis, percaya diri, bersih dan kuat. Maka didapatlah logogram dengan warna seperti ini :
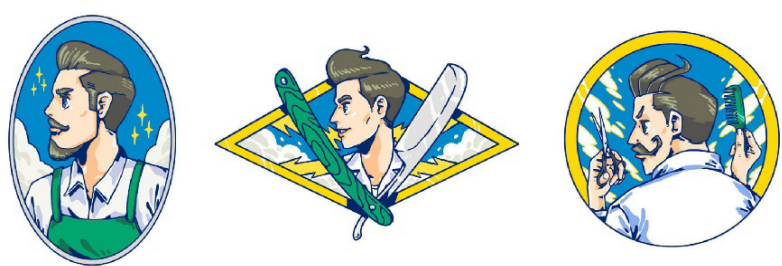

Gambar 7. Alternatif Logo Barberson Haircut (Sumber : Arif Suryawan, 2019)

Setelah visual logo dan tipografi telah terpilih, langkah selanjutnya adalah menentukan komposisi logo dengan menggabungkan tipografi dengan visual logo.
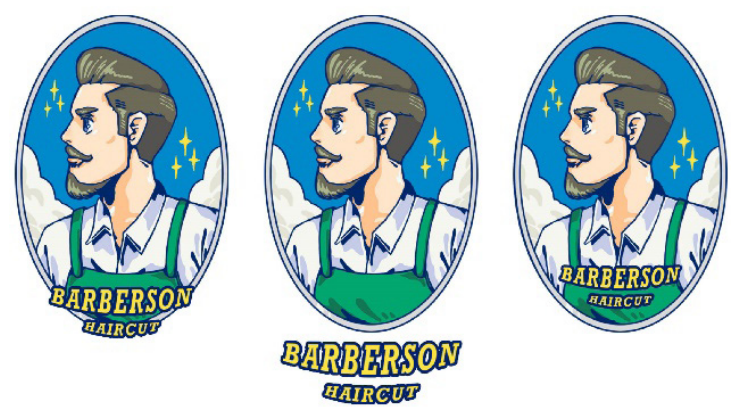

Gambar 8. Pemilihan Komposisi Logo Barberson Haircut (Sumber : Arif Suryawan, 2019)

Thumbnail logogram dan logotype yang terpilih selanjutnya digabungkan menjadi kesatuan logo dan dikomposisikan dengan baik. Berikut adalah penampilan komposisi logo yang terpilih :

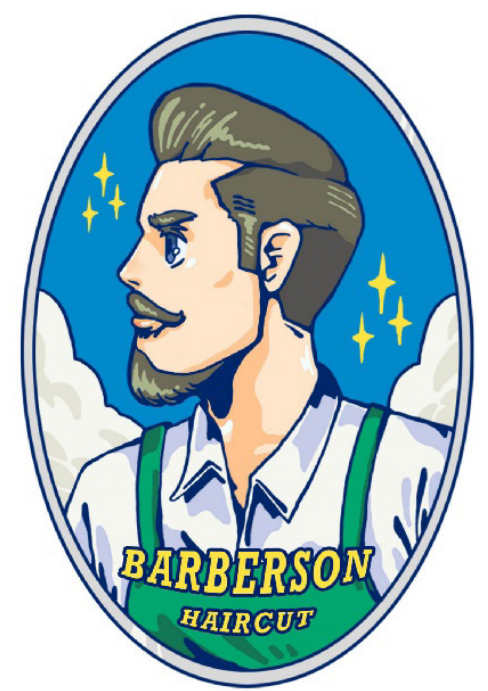

Gambar 9. Review logo Barberson

(Sumber : Arif Suryawan, 2019)

Berdasarkan tabel kriteria logo yang dikemukakan oleh Suryanto Rustan (2009) perancangan logo Barberson bisa mengacu pada tabel tersebut dan dapat diuraikan sebagai berikut :

\section{a. Bentuk}

Bentuk logogram menggunakan unsur visual culture Barbershop dengan tampilan garisgaris dan hal ini menjadi pembeda dengan logo pesaing. Pada logogram juga terdapat inisial yaitu nama dari objeknya sendiri "Barberson Haircut". Perpaduan warna pop yang dinamis 
menambah karakteristik tampilan logo. Pemilihan jenis huruf disesuaikan dengan gaya logogram serta mengalami modifikasi sehingga tampilan logo terlihat harmonis dan selaras.

\section{b. Warna}

Warna logo yang dipilih yaitu, biru dan kuning sehingga terkesan fresh dan mudah diingat. Warna biru identik dengan warna kebersihan karena objek tersebut merupakan jasa cukur rambut. Pemilihan warna tersebut dimaknai juga dengan pop culture, artinya objek tersebut memiliki sisi sejarah bahwa dahulunya barbershop.

\section{c. Ukuran}

Logo memiliki bentuk yang simpel dan ukuran fleksibel sehingga logo bisa dikondisikan dan dikomposisikan sesuai kondisi media yang dipakai. Berdasarkan uraian di atas logo Barberson Haircut bisa dikatakan sudah memiliki kriteria umum seperti kriteria logo yang dikatakan Suryanto Rustan. Logo memliki bentuk yang unik, simpel, dan fleksibel, warna yang simpel dan fleksibel pula, serta memiliki ukuran yang fleksibel.

\section{Final Artwork}

\section{a. Penerapan Warna Logo}

Standarisasi warna yang diterapkan untuk logo adalah warna yang dipakai untuk logo itu sendiri, yaitu warna biru, kuning, hijau, putih, coklat.

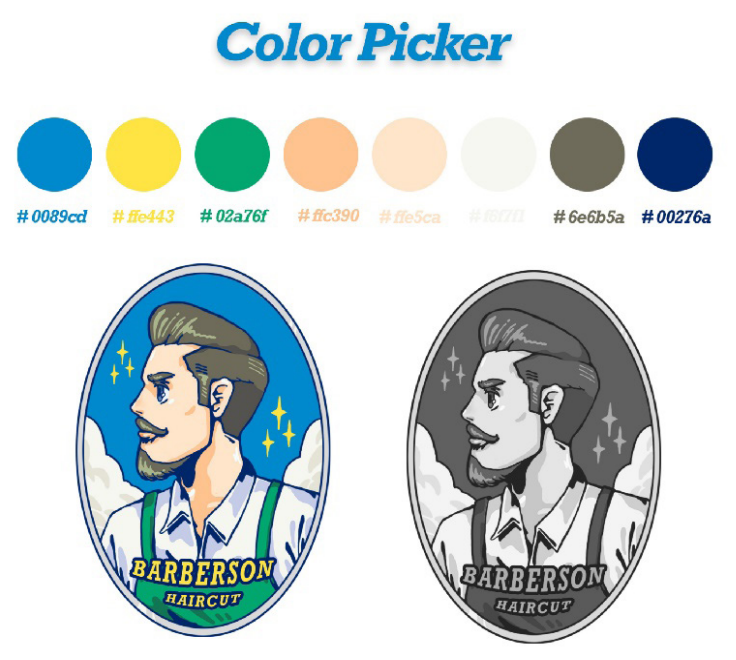

Gambar 10. Color Picker Logo Barberson Haircut (Sumber : Arif Suryawan, 2019)

\section{a. Clear Space Area}

Ketika logo diterapkan pada background yang ramai clear space area berfungsi untuk memberikan ruang kosong pada logo sehingga logo tidak terganggu oleh objek yang lain. Ruang kosong ini hanya diperkenankan untuk logo saja dan tidak diperbolehkan objek lain untuk mengisi ruang tersebut.

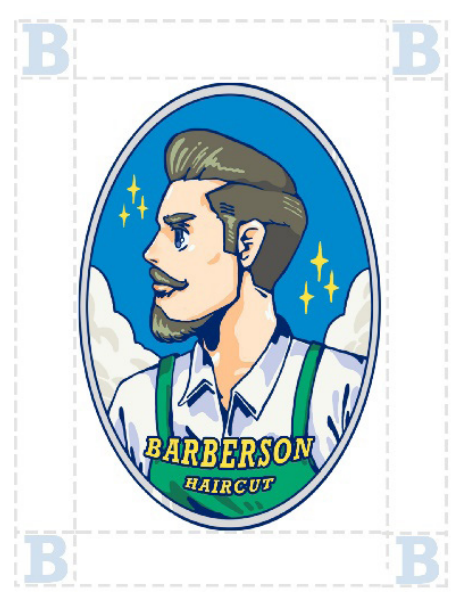

Gambar 11. Clear space area Barberson Haircut (Sumber : Arif Suryawan, 2019)

Clear space area logo Barberson Haircut berukuran sebesar huruf "B" pada logotype. Dalam menempatkan logo, harus ditambahkan masing-masing satu modul (B) pada tiap sisi 
logo sehingga terdapat ruang kosong di sekeliling logo. Ruang kosong ini dimaksudkan untuk memisahkan logo dengan unsur lain seperti teks, gambar, atau bidang warna lainnya sehingga keutuhan bentuk tetap terjaga.

\section{b. Size System Logo}

Ukuran paling besar logo Barberson Haircut pada skala $100 \%$ adalah $20 \mathrm{~cm} \times 7,639 \mathrm{~cm}$, diperkecil $75 \%$ menjadi $15 \mathrm{~cm}$ x $5,729 \mathrm{~cm}$, dikecilkan lagi 50\% menjadi $10 \mathrm{~cm}$ x $3,819 \mathrm{~cm}$, dan pada skala $25 \%$ menjadi $5 \mathrm{~cm} \mathrm{x} 1,191 \mathrm{~cm}$ serta ukuran paling kecil logo adalah dengan panjang proporsional $2,5 \mathrm{~cm}$.
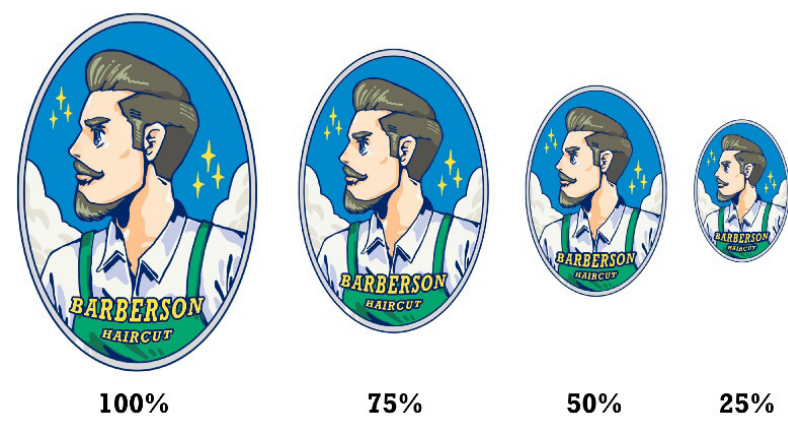

Gambar 12. Size System Logo Barberson Haircut (Sumber : Arif Suryawan, 2019

\section{B. Desain Stationey Set dan Merchandise}

Logo yang telah di rancang dan dipilih sebelumnya akan diaplikasikan di berbagai media yang menjadi penunjang dari sebuah produk seperti stationey set dan merchandise. Stationey Set dan Merchandise tersebut antara lain adalah kartu nama, kartu identitas, stempel, nota, appron, paper bag, pomade, pin, dan t-shirt.

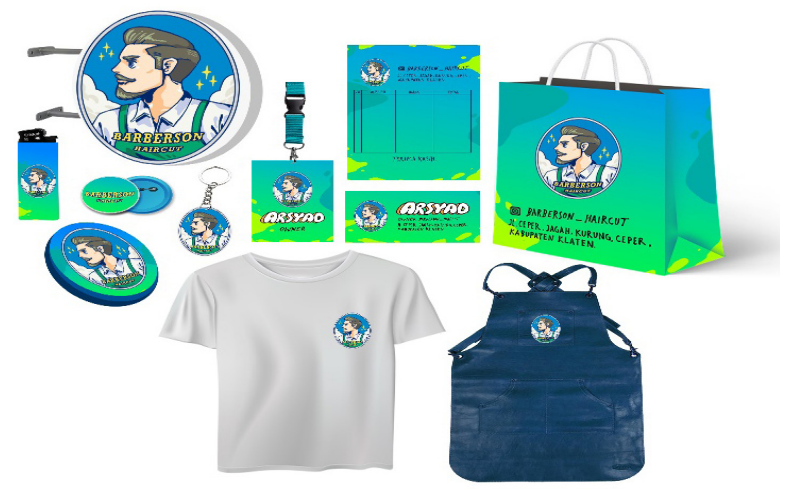

Gambar 13. Stationey Set dan Merchandise (Sumber : Arif Suryawan, 2019)

\section{Konsep Iklan \\ 1. Kreatif Brief Iklan \\ a. What to say}

Mengkomunikasikan perubahan logo Barberson Haircut yang baru kepada target audience. Di mana pesan yang ingin disampaikan bahwa perusahaan hadir dengan logo baru dan konsep baru, lebih berkarakter, serta eksklusif dan elegan serta mempromosikan Barberson Haircut di Acara Pentas Musik Akhir Tahun.

b. Segmentasi

Pria berusia 15 tahun ke atas yang datang di Acara Event Pentas Musik Akhir Tahun.

\section{c. Tone and manner}

Modern, elegant dan karakteristik

d. Positioning

Barberson Haircut merupakan tempat cukur rambut di Klaten pilihan anak muda.

e. USP

Mempunyai Fasilitas perawatan rambut istimewa.

\section{Konsep Visual Iklan}

Media promosi yang akan digunakan Barberson Haircut menggunakan teknik ilustrasi. Dengan ilustrasi suasana Barberman sedang mencukur 
wisatawan yang berkunjung di booth Barberson Haircut yang berada di Acara Pentas Musik Akhir Tahun. Dengan menggunkan gaya ilustrasi pop art dengan ciri khas warna yang fun.

a. Konsep Verbal iklan

\section{Headline}

Headline yang digunakan dalam beberapa aplikasi iklan ini adalah "New Year New Style". Tujuannya adalah untuk menunjukan pada target audiens bahwa menyambut tahun yang baru di Acara Pentas Musik Akhir Tahun, tidak lengkap bila penampilan rambut juga harus baru. Pesan verbal yang disampaikan dibuat cukup singkat namun mampu memperkuat visualnya dibuat menggunakan bahasa inggris karena disesuaikan dengan target audiensnya.

\section{Body Copy}

Body copy yang digunakan dalam beberapa aplikasi iklan ini adalah "Sambut tahun baru dengan style baru, Barberson Haircut hadir di Acara Pentas Music Akhir Tahun, Alun-alun Klaten tanggal 31 desember jam 06:00 - sampai selesai datang dan dapatkan promo menarik".

\section{Tipografi}

Jenis tipografi yang digunakan adalah tipografi yang mempunyai unsur keterbacaan yang jelas. Jenis font yang di gunakan pada headline adalah "Font Dekoratif, dimana font tersebut memiliki kesan fun elegan namun tetap memiliki keterbacaan yang jelas.

\section{Media Promosi}

Beberapa iklan yang dibuat seagai media promosi diantaranya adalah print ad (iklan cetak), visual post sosial media, sticar, dan roll banner.
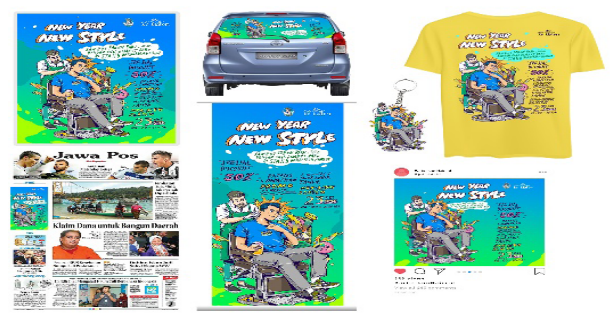

Gambar 14. Media Promosi Barberson Haircut (Sumber : Arif Suryawan, 2019)

\section{H. Visual Merchandising}

Visual merchandising mengkombinasikan kemampuan menata produk, grafis dan interior untuk menstimulasi dan menciptakan display sedemikian rupa sehingga didapatkan tampilan yang terlihat seperti yang diinginkan, seperti menciptakan suasana ceria, semangat, hangat atau cozy yang membuat orang tertarik untuk membeli. Seperti membuat window display ataupun display pendukung interior secara keseluruhan dari sebuah department store misalnya outlet dari suatu brand terlihat menarik dan bisa menggugah konsumen untuk masuk dan membeli produk yang dijual di dalamnya. Berikut visual merchandising:

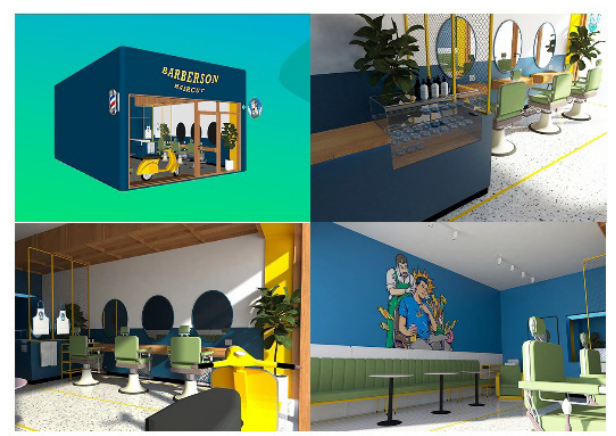

Gambar 15. Visual merchandising Barberson Haircut

(Sumber : Arif Suryawan, 2019) 


\section{KESIMPULAN}

Perancangan ulang corporate identity Barberson Haircut bertujuan untuk merancang corporate identity yang konsisten dan menggambarkan karakter perusahaan. Perancangan tersebut menggunakan gaya culture barbershop dan pop art sebagai ide dasar perancangan yang mampu memperkuat karakter atau identitas perusahaan sebagai tempat cukur rambut yang terkonsep dan menjadi pilihan di Kota Klaten dan sekitarnya. Hasil dari perancangan ini berupa sebuah sistem identitas visual baru yang terdiri dari logo, tipografi, warna, serta gaya beriklan yang baru. Media apalikasi corporate identity terdiri dari, stationery set, kemasan, merchandising, dan media promosi. Aplikasi pada keseluruhan media dibuat dengan tujuan mempromosikan dan memperkenalkan Barberson Haircut dengan corporate identity yang baru.

\section{Saran dan rekomendasi:}

Berdasarkan perancangan ulang dan strategi promosi maka bagi perancang berikutnya jika ingin melakukan perancangan terkait corporate identity maka riset adalah yang utama. Setelah itu barulah dilakukan sketsa yang terbaik dan dipilih untuk menjadi dasar kekuatan desain dan mengaplikasikannya dengan strategi periklanan media yang tepat dan kaitannya dengan bidang usaha jasa seperti pada usaha Baberson Haircut.

Penelitian dan perancangan identitas visual memerlukan sebuah kajian dan evaluasi, maka bagi penelitian selanjutnya jika belum ada yang terkait dalam perancangan ini dapat dilakukan riset dan pendekatan visual teori lainnya terhadap pendekatan promosi dan identitas visual suatu perusahaan.

\section{DAFTAR PUSTAKA}

A. Shimp, Terence. 2000. Periklanan Promosi: Aspek Tambahan Komunikasi Pemasaran Terpadu. Jakarta : Erlangga

Handriyotopo, 2018. Kapita Selekta Media Budaya Komunikasi Visual. Surakarta: ISI Press

Jefkins, Frank. 1997. Periklanan. Jakarta : Erlangga

M. Linggar Anggoro. 2001. Teori dan Profesi Kehumasan serta Aplikasinya di Indonesia. Jakarta : Bumi Aksara

Rustan, Surianto. 2009. Mendesain Logo. Jakarta : PT Gramedia Pustaka Utama

Sachari, Agus dan Yan Yan Sunarya. 2002. Sejarah dan Perkembangan Desain \& Dunia Kesenirupaan di Indonesia. Bandung : Penerbit ITB

Sugiyono, 2015. Metode Penelitian Kombinasi. Bandung : Alfabeta. 